\title{
Spin-state-dependent peroxymonosulfate activation of single-atom M- N moieties via a radical-free pathway
}

Jie Miao ${ }^{1}$, Yuan Zhu ${ }^{1}$, Junyu Lang ${ }^{1}$, Jingzhen Zhang ${ }^{1}$, Shixian Cheng ${ }^{1}$, Baoxue Zhou ${ }^{1}$, Lizhi Zhang ${ }^{2}$, Pedro J J. Alvarez ${ }^{3}$, Mingce Long, ${ }^{1 *}$

1 School of Environmental Science and Engineering, Key Laboratory for Thin Film and Microfabrication of the Ministry of Education, Shanghai Jiao Tong University, Shanghai 200240, China

2 Key Laboratory of Pesticide \& Chemical Biology of Ministry of Education, Institute of Environmental \& Applied Chemistry, Central China Normal University, Wuhan 430079, PR China

${ }^{3}$ Department of Civil and Environmental Engineering, Rice University, Houston, TX 77005, United States

Email: long mc@sjtu.edu.cn

Number of pages: 33

Number of texts: 5

Number of figures: 22

Number of tables: 4 


\section{List of supporting information}

\begin{tabular}{|c|c|c|}
\hline & Content & Page \\
\hline Text S1 & Material synthesis & S4 \\
\hline Text S2 & Characterization & S4 \\
\hline Text S3 & Evaluation of catalytic performance & S5 \\
\hline Text S4 & Electrochemical test & S5 \\
\hline Text S5 & Theoretical calculations & S5-S6 \\
\hline Figure S1 & $\begin{array}{l}\text { HAAD-STEM images for (a) Fe-N-CNTs and (c) Fe-N-CNTs } \\
\text { after acid treatment in } 5 \mathrm{M} \mathrm{H}_{2} \mathrm{SO}_{4} \text { for } 7 \mathrm{~h} \text { at } 80^{\circ} \mathrm{C} \text {; (b) EDS } \\
\text { images for Fe-N-CNTs }\end{array}$ & S7 \\
\hline Figure S2 & HAAD-STEM images for Mn-N-CNTs & S8 \\
\hline Figure S3 & HAAD-STEM images for Ni-N-CNTs & S9 \\
\hline Figure S4 & $\begin{array}{l}\text { HR-TEM images of N-CNTs and different M-N-CNTs } \\
\text { catalysts }\end{array}$ & $\mathrm{S} 10$ \\
\hline Figure S5 & XRD patterns of different M-N-CNTs catalysts & $\mathrm{S} 11$ \\
\hline Figure S6 & $\begin{array}{l}\mathrm{N}_{2} \text { adsorption/desorption profiles of CNTs, N-CNTs and } \\
\text { different M-N-CNTs catalysts }\end{array}$ & $\mathrm{S} 12$ \\
\hline Figure S7 & XPS spectra of N 1s for different M-N-CNTs catalysts & $\mathrm{S} 13$ \\
\hline Figure S8 & $\begin{array}{l}\text { (a) Fourier transform (FT) } \mathrm{k}^{3} \text {-weighted } \chi(\mathrm{k}) \text {-function of the } \\
\text { EXAFS spectra of the Co K-edge of the Co-N-CNTs; (b) } \\
\text { Corresponding Co K-edge EXAFS fitting curve of Co-N- } \\
\text { CNTs; (c) quantitative EXAFS fitting curve at K space }\end{array}$ & S14 \\
\hline Figure S9 & $\begin{array}{l}\text { (a) } \mathrm{pH} \text { changes during SMX oxidation; (b) negligible effect of } \\
\mathrm{pH} \text { on SMX oxidation in the Co-N-CNTs/PMS system; } \\
\left.\text { Reaction conditions: }[\mathrm{SMX}]_{0}=10 \mathrm{mg} \mathrm{L}^{-1} \text {, [catalyst }\right]=0.1 \mathrm{~g} \\
\left.\mathrm{~L}^{-1},[\mathrm{PMS}]_{0}=1 \mathrm{mM} \text {, [Borate }\right]_{\text {buffer }}=0.2 \mathrm{M} \text {. }\end{array}$ & $\mathrm{S} 15$ \\
\hline Figure S10 & $\begin{array}{l}\text { The first-order kinetics of SMX oxidation in (a) CNTs/PMS, } \\
\text { N-CNTs/PMS and (b) M-N-CNTs/PMS systems. }\end{array}$ & $\mathrm{S} 16$ \\
\hline Figure S11 & $\begin{array}{l}\text { HAAD-STEM images for Co-N-CNTs after hot acid etching } \\
\text { in }\left(5 \mathrm{M} \mathrm{H}_{2} \mathrm{SO}_{4}, 7 \mathrm{~h}, 80{ }^{\circ} \mathrm{C}\right)\end{array}$ & S17 \\
\hline Figure S12 & $\begin{array}{l}\text { Comparison of (a) catalytic activities of Co-N-CNTs, Co-N- } \\
\text { CNTs after hot acid etching, Co cluster-CNTs and (b) Fe-N- } \\
\text { CNTs after hot acid etching (c) The reaction rate constants } \\
\left(k_{o b s}\right) \text { of Co-N-CNTs, Co-N-CNTs after hot acid etching, Co } \\
\text { cluster-CNTs and N-CNTs. }\end{array}$ & $\mathrm{S} 18$ \\
\hline Figure S13 & $\begin{array}{l}\text { Quenching experiments in (a) N-CNTs/PMS system and (b) } \\
\text { Co-N-CNTs/PMS system; EPR spectra of (c) DMPO and } \\
\text { (d) }{ }^{1} \mathrm{O}_{2} \text { in different reaction systems }\end{array}$ & S19 \\
\hline Figure S14 & $\begin{array}{l}\text { (a) GC-MS analysis for DMSO and } \mathrm{DMSO}_{2} \text { at reaction time }= \\
5 \mathrm{~min} \text { in different systems; (b) DMSO degradation and } \\
\mathrm{DMSO}_{2} \text { conversion obtained at different reaction time in } \\
\text { different systems; Reaction conditions: }[\mathrm{DMSO}]_{0}=20 \mu \mathrm{M} \text {, } \\
{[\text { catalyst }]=0.1 \mathrm{~g} \mathrm{~L}^{-1},[\mathrm{PMS}]_{0}=1 \mathrm{mM}, \mathrm{T}=25^{\circ} \mathrm{C} \text {. }}\end{array}$ & $\mathrm{S} 20$ \\
\hline
\end{tabular}

Figure S15 PMS adsorption in M-N-CNTs/PMS systems $(\mathrm{M}=\mathrm{Fe}, \mathrm{Mn}$, 
Ni) without SMX

Figure S16 PMS adsorption capacities over M-N-CNTs catalyst $\quad$ S22

$\begin{array}{lll}\text { Figure S17 The first-order kinetics of SMX oxidation in N-CNTs/PMS } & \text { S23 }\end{array}$ and $\mathrm{M}-\mathrm{N}-\mathrm{CNTs}(\mathrm{M}=\mathrm{Co}, \mathrm{Fe}, \mathrm{Mn}, \mathrm{Ni}) / \mathrm{PMS}$ systems with different PMS dosage. $[\mathrm{SMX}]_{0}=10 \mathrm{mg} \mathrm{L}^{-1}$, [catalyst $]=0.1 \mathrm{~g}$ $\mathrm{L}^{-1},[\mathrm{MeOH}]_{0}=1 \mathrm{M}, \mathrm{pH}_{\text {initial }}=6.8, \mathrm{~T}=25^{\circ} \mathrm{C}$

Figure S18 Open-circuit potential curves with different PMS dosage on

CNTs and M-N-CNTs electrodes

Figure S19 PMS* potentials in N-CNT/PMS and M-N-CNTs/PMS

systems with different PMS dosage

Figure S20 The electrochemical impedance spectroscopy (EIS) plots of

$\mathrm{M}-\mathrm{N}-\mathrm{CNTs}$ and N-CNTs electrodes recorded at $-0.3 \mathrm{~V}$ vs $\mathrm{Ag} / \mathrm{AgCl}$ in $50 \mathrm{mM} \mathrm{Na}_{2} \mathrm{SO}_{4}$ solution.

Figure S21 ZFC/FC curves over different M-N-CNTs catalysts measured at $1 \mathrm{kOe}$

Figure S22 The configuration of PMS adsorption on (a) Fe-N-CNTs; (b) Mn-N-CNTs and (c) Ni-N-CNTs

Table S1 The specific surface areas (SSAs) for CNTs, N-CNTs and M$\mathrm{N}-\mathrm{CNT}$ catalysts and Metal contents in M-N-CNTs and Co cluster-CNTs detected by ICP-MS measurement

Table S2 The relative contents of different elements on the surface of different catalysts summarized from the XPS results

Table S3 Structural parameters with errors of the samples obtained by fitting the EXAFS data. There are the average coordination number $(N)$, path distance $(R)$, Debye-Waller factor $\left(\sigma^{2}\right)$, threshold energy correction $(\Delta \mathrm{E})$, and the R-Factor of the fitting

Table S4 The spin states, theoretical $\mu_{\text {eff }}$ and calculated $\mu_{\text {eff }}$ of different metals in M-N-CNTs catalysts 
Text S1. Material synthesis. Carbon nanotubes (CNTs, $>95 \mathrm{wt} \%$, length: $\sim 50 \mu \mathrm{m})$ were purchased from Chengdu Organic Chemicals Co., Ltd, which were washed with $\mathrm{HCl}$ solution $(3 \mathrm{M})$ at room temperature for $24 \mathrm{~h}$ before use. The M-N-CNT (M=Co, Fe, Mn, Ni) catalysts were prepared by a method of metal chelation-pyrolysis. In the synthesis, the metal source is the acetylacetonate (acac), such as $\left(\mathrm{Co}(\mathrm{acac})_{2}, \mathrm{Fe}(\mathrm{acac})_{3}, \mathrm{Mn}(\mathrm{acac})_{3}\right.$ and $\mathrm{Ni}(\mathrm{acac})_{2}$. 2,2'-bipyridine (BPY) was selected as the metal chelator. Taken Co-N-CNTs as an example, $0.017 \mathrm{mmol} \mathrm{Co(acac})_{2}$ and $0.034 \mathrm{~mol} \mathrm{BPY}$ were dissolved in $20 \mathrm{~mL}$ absolute ethanol under continuous magnetic stirring for $20 \mathrm{~min}$. Then, $100 \mathrm{mg}$ CNTs was added into the above homogeneous solution, followed by continuous stirring at room temperature for $10 \mathrm{~min}$. Next, the mixture was heated at $60^{\circ} \mathrm{C}$ until ethanol was completely evaporated. The obtained precursor Co@BPY@CNTs was calcined in Ar atmosphere at $800{ }^{\circ} \mathrm{C}$ for $2 \mathrm{~h}$. The pyrolyzed product was etched in $3.6 \mathrm{M} \mathrm{H}_{2} \mathrm{SO}_{4}$ at $25^{\circ} \mathrm{C}$ for $12 \mathrm{~h}$ to remove inactive Co species. Finally, the sample of Co-N-CNTs was washed with deionized water to neutral and dried at $60{ }^{\circ} \mathrm{C}$ overnight. Moreover, other M-N-CNTs $(\mathrm{M}=\mathrm{Fe}, \mathrm{Mn}, \mathrm{Ni})$ products were prepared via the similar synthetic procedure of Co-N-CNTs, and the initial mass fraction of transition metal is $1.0 \mathrm{wt} \%$ of CNTs. For comparison, N-CNTs was prepared with only BPY but no metal sources, Co cluster-CNTs was synthesized without BPY. To remove the formed metal clusters, the obtained M-N-CNTs and Co cluster-CNTs were further treated in $5 \mathrm{M} \mathrm{H}_{2} \mathrm{SO}_{4}$ at $70{ }^{\circ} \mathrm{C}$ for $8 \mathrm{~h}$, and the catalysts were then washed for several times until its $\mathrm{pH}$ reached neutral.

Text S2. Characterization. The metal contents in M-N-CNT catalysts were measured by an inductively coupled plasma mass spectrometer (ICP-MS, ThermoFisher Scientific). The crystal phases and morphologies of catalysts were determined by Rigaku D/max-2200/PC X-Ray diffraction (XRD) and TECNA1 G2F20 transmission electron microscopy (TEM), respectively. $\mathrm{N}_{2}$ adsorptiondesorption isotherms were recorded on a Nova 2200e gas sorption analyzer (Quantachrome Instruments). High-angle annular dark-field scanning transmission electron microscopy (HAADFSTEM) was conducted on a JEOL JEM-ARF200F atom resolution analytical microscope. XPS analyses were performed on an Axis Ultra DLD system (Shimadzu/Kratos) of X-ray photoelectron spectroscopy (XPS). Raman spectra were obtained on a Bruker Senterra R200-L dispersive Raman microscope at $532 \mathrm{~nm}$. Zero field cooled (ZFC) and field cooled (FC) measurements were executed by magnetic property measurement system (MPMS-3, Quantum Design) under H=1 kOe for temperaturedependent $(2 \mathrm{~K}-400 \mathrm{~K})$ magnetization measurement. The Co K-edge X-ray adsorption fine structure 
(XAFS) tests were performed in fluorescence mode on beamline TLS07A1 with electron energy of 1.5 $\mathrm{GeV}$ and an average current of $250 \mathrm{~mA}$ which is located in the National Synchrotron Radiation Research Center (NSRRC) of Taiwan, China. EXAFS data analysis and fitting were processed by Athena software.

Text S3. Evaluation of catalytic performance. The performance of M-N-CNT catalysts for peroxymonosulfate (PMS) activation were evaluated by sulfamethoxazole (SMX) degradation. SMX degradation was performed in $50 \mathrm{~mL}$ SMX solution $\left(10 \mathrm{mg} \mathrm{L}^{-1}\right.$, initial $\left.\mathrm{pH}=6.8\right)$, containing $1.0 \mathrm{mM}$ PMS and $0.1 \mathrm{~g} \mathrm{~L}^{-1}$ catalyst at $25^{\circ} \mathrm{C}$. The concentration of SMX was detected by a high-performance liquid chromatography (HPLC, Shimadzu LC-2010AHT). Residual PMS was determined by the 2,2'azino-bis (3-ethylbenzothiazoline-6-sulfonic acid) diammonium salt (ABTS) method. ${ }^{1-2}$ Electron paramagnetic resonance (EPR) spectra of reactive oxygen species (ROS) in M-N-CNTs/PMS system were identified by a Bruker microEPR spectrometer.

Text S4. Electrochemical test. The potentials of PMS complexes on M-N- CNT surface was carried out on a standard three-electrode cell using a CHI 760 workstation, in which an $\mathrm{Ag} / \mathrm{AgCl}$ electrode was used as the reference electrode, $\mathrm{Pt}$ wire as the counter electrode, and $50 \mathrm{mM} \mathrm{Na}_{2} \mathrm{SO}_{4}$ solution (100 $\mathrm{mL}$ ) as the electrolyte solution. The M-N-CNT-coated glassy carbon electrode (M-N-CNT-GCE) was prepared by dripping $20 \mu \mathrm{L}$ mixed ethanol solution with M-N-CNTs $\left(20 \mathrm{~g} \mathrm{~L}^{-1}\right)$ and 5\% Nafion solution. After drying, the potential of M-N-CNT-GCE was monitored by the chronopotentiometry method. ${ }^{3}$ Quantitative PMS addition changed the stable potential of M-N-CNT-GCE, and the potential difference represents the potential of PMS active complexes on M-N-CNT surface.

Text S5. Theoretical calculations. The spin polarized electronic structures of all M-N-CNT $\left(\mathrm{MN}_{4}\right)$ models were computed with density function theory (DFT) using projected augmented wave (PAW) approach for calculation of energies, which is implemented in Vienna Ab initio Simulation Package (VASP) code. ${ }^{4-7}$ The exchange-correlation interactions were treated with the generalized gradient approximation (GGA) parameterized by Perdew-Burke-Ernzerhof (PBE) functions. ${ }^{8}$ The cutoff energy of plane-wave basis was set to $450 \mathrm{eV}$. The Monkhorst-Pack meshes of $4 \times 4 \times 1 \mathrm{k}$-point sampling in the Brillouin zone were employed for $\mathrm{MN}_{4}$ model and adsorbed models. Periodic boundary conditions were used in all directions and a vacuum region of $25 \AA$ was introduced along the out-of-plane direction to eliminate spurious interactions among periodic images. The atomic positions were fully relaxed with convergence tolerance for energy and force were set to be $10-5 \mathrm{eV}$ and $0.03 \mathrm{eV} / \AA$, 
respectively. The charge density and electron transfer were analyzed by the Bader code. ${ }^{9}, 10$ The amount of net charges transfer $(\mathrm{Q})$ was calculated by the total Bader charge difference between free PMS and adsorbed PMS. The adsorption energy $\left(E_{a d s}\right)$ of PMS onto different M-N-CNTs can be defined as:

$\mathrm{E}_{\mathrm{ads}}=\mathrm{E}_{\mathrm{PMS}+\mathrm{MN} 4}-\mathrm{E}_{\mathrm{PMS}}-\mathrm{E}_{\mathrm{MN} 4}$

where $\mathrm{E}_{\mathrm{PMS}+\mathrm{MN} 4}, \mathrm{E}_{\mathrm{PMS}}$ and $\mathrm{E}_{\mathrm{MN} 4}$ represent for the total energy of the PMS adsorbed $\mathrm{MN}_{4}$ sites, free PMS and $\mathrm{MN}_{4}$, respectively. 


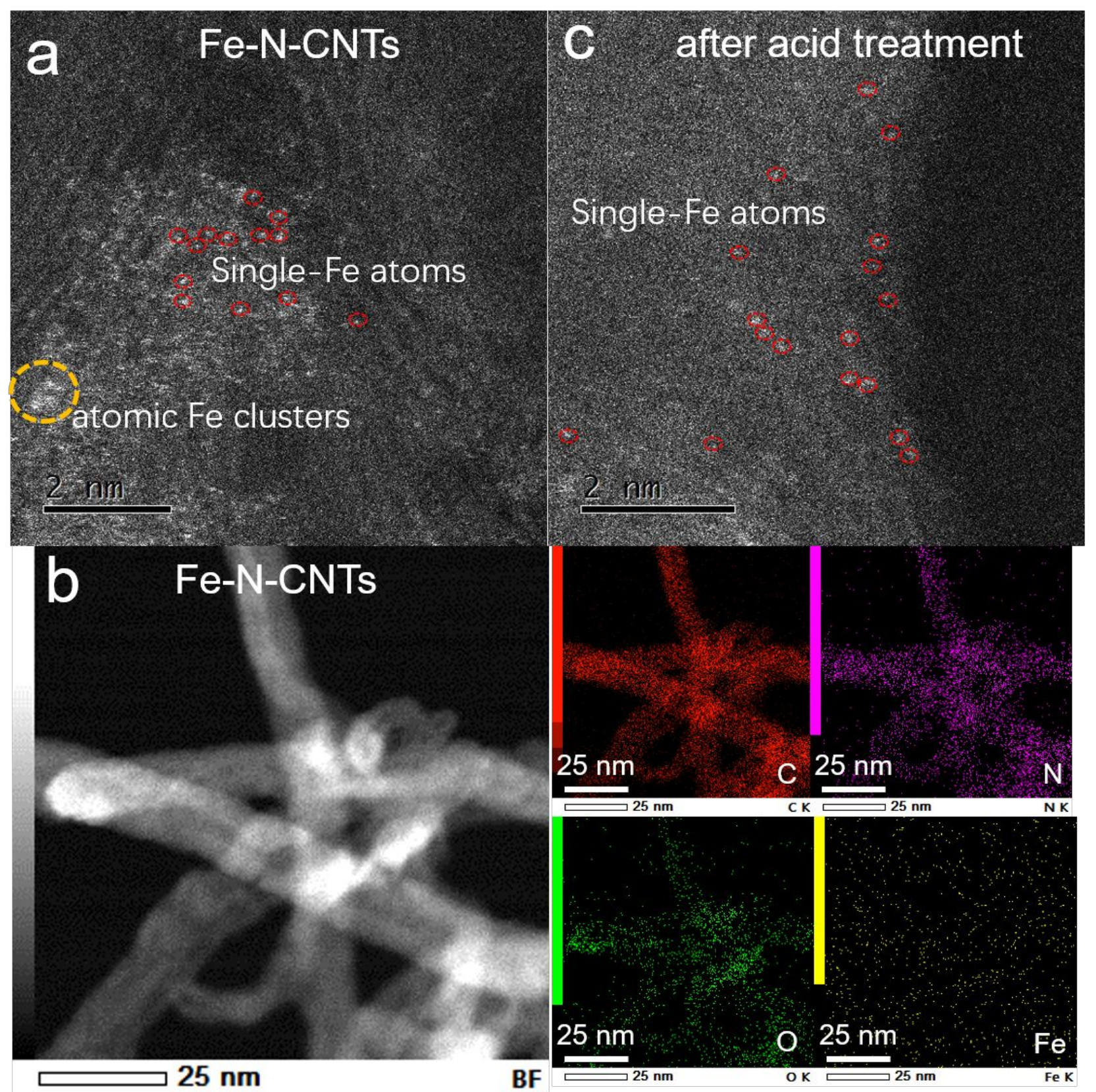

Figure S1. HAAD-STEM images for (a) Fe-N-CNTs and (c) Fe-N-CNTs after acid treatment in $5 \mathrm{M}$ $\mathrm{H}_{2} \mathrm{SO}_{4}$ for $7 \mathrm{~h}$ at $80^{\circ} \mathrm{C}$; (b) EDS images for Fe-N-CNTs. 


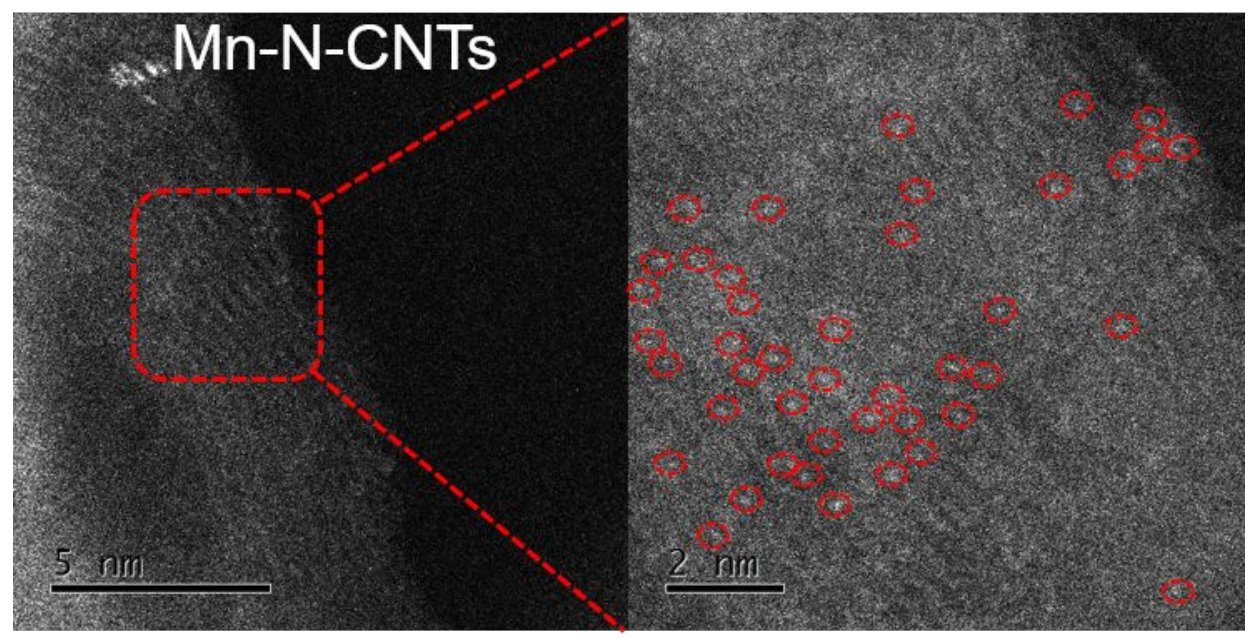

Figure S2. HAAD-STEM images for Mn-N-CNTs. 


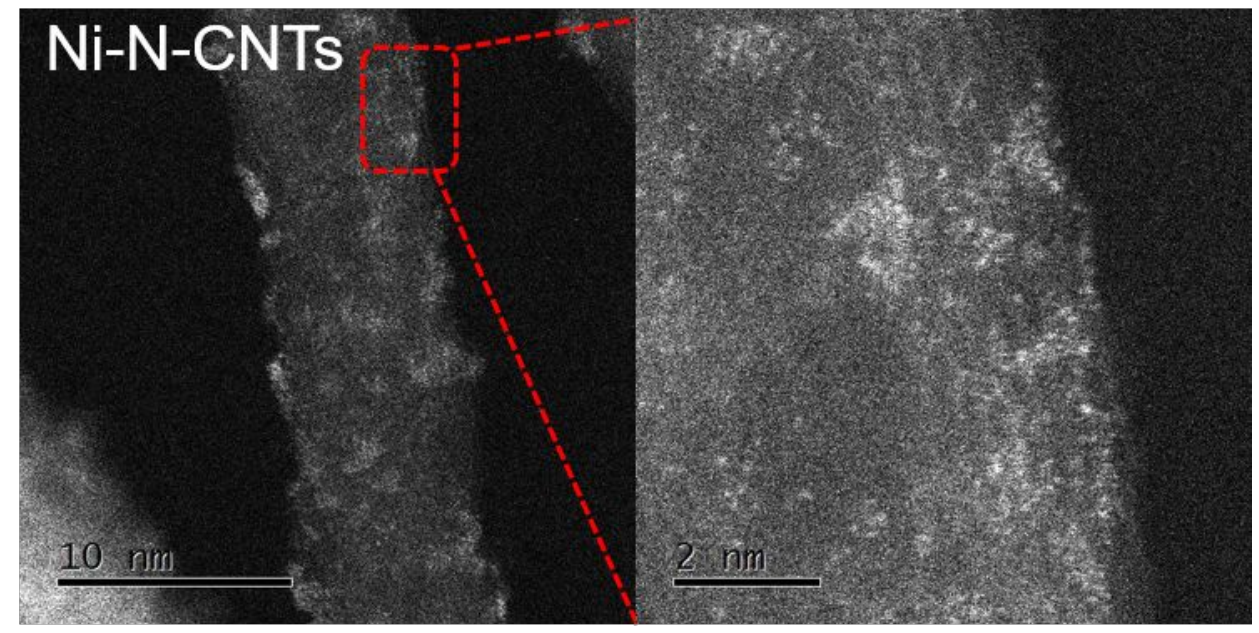

Figure S3. HAAD-STEM images for Ni-N-CNTs. 


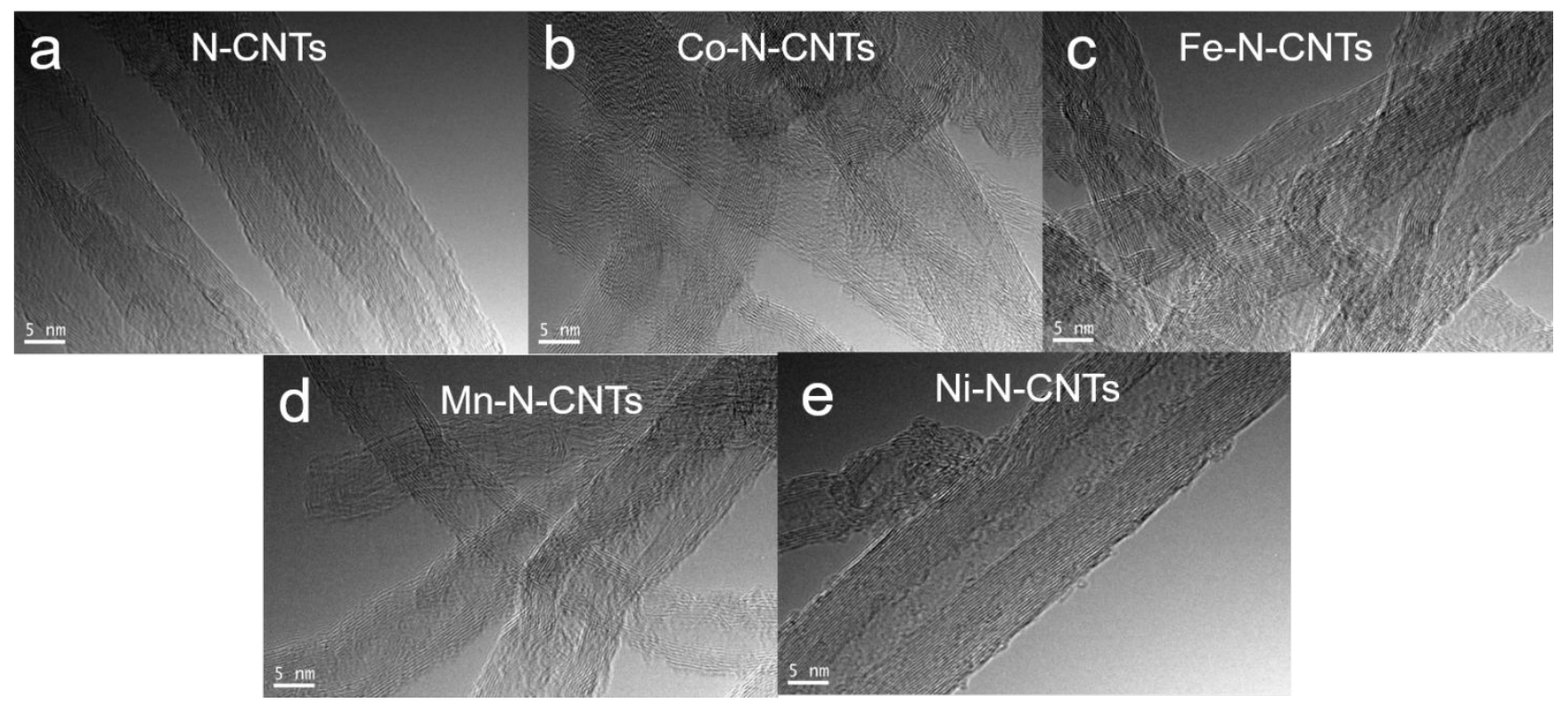

Figure S4. HR-TEM images of N-CNT and M-N-CNT catalysts. 


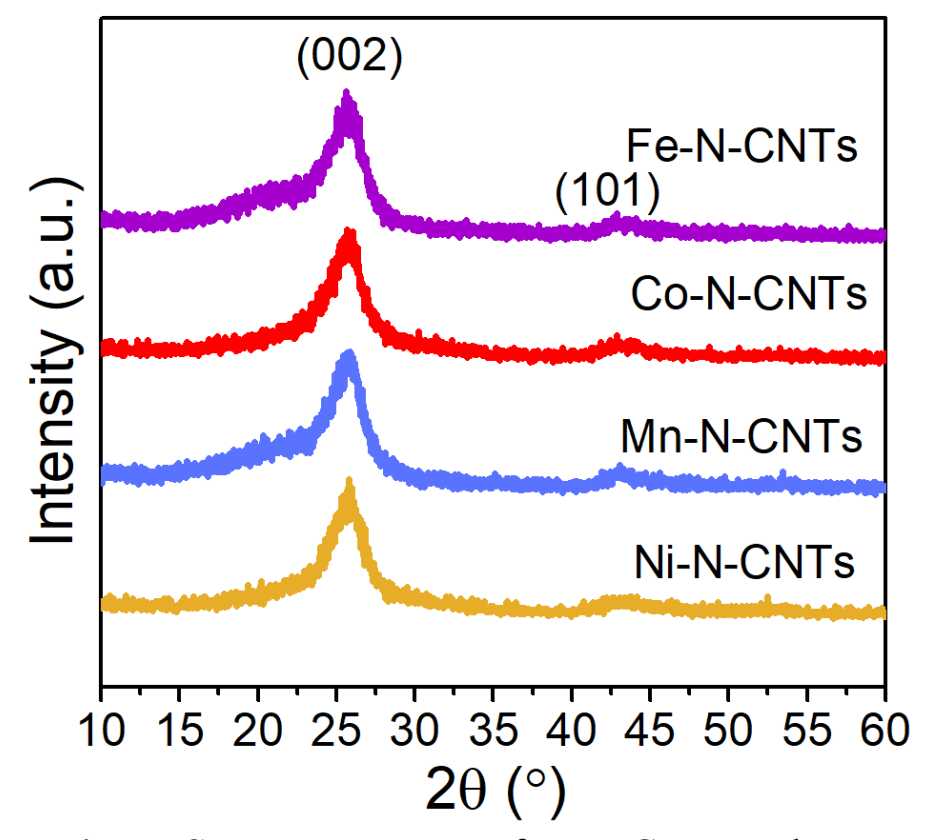

Figure S5. XRD patterns of M-N-CNT catalysts. 

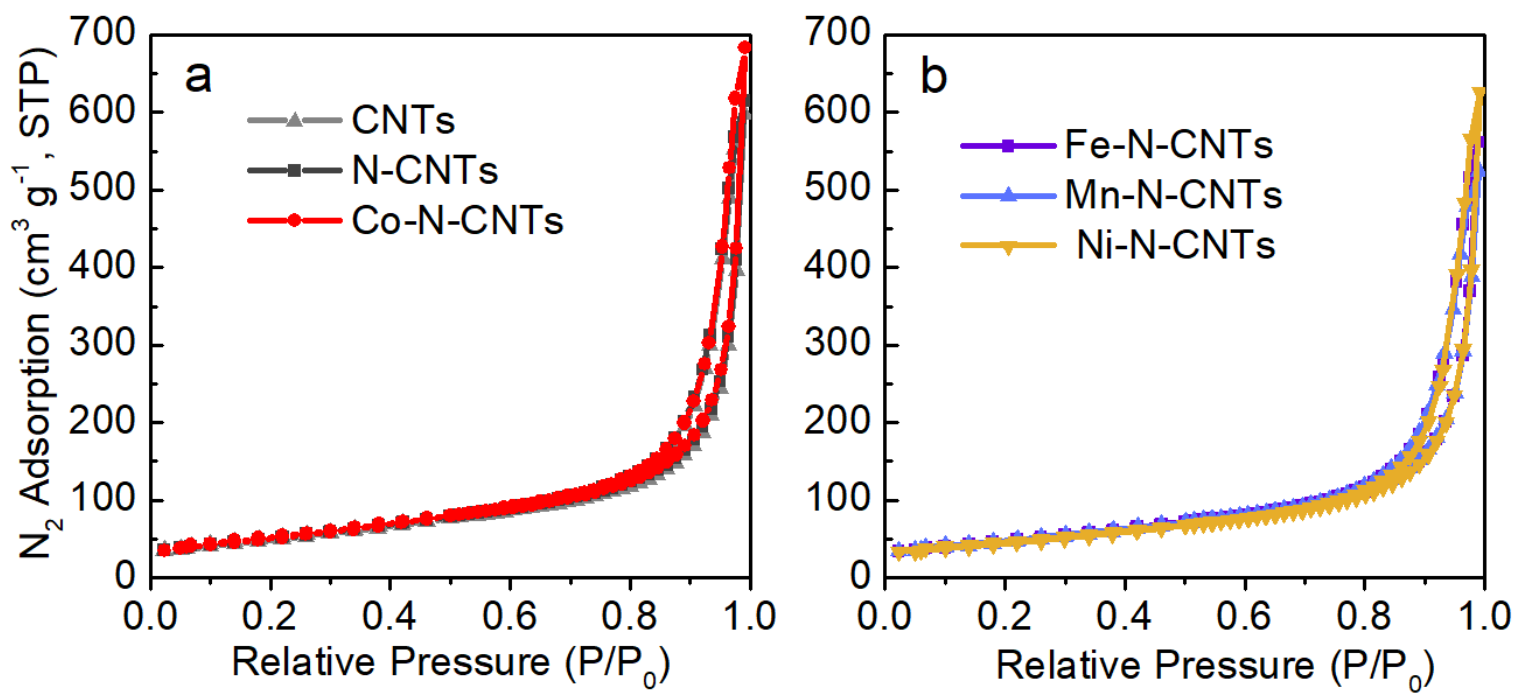

Figure S6. $\mathrm{N}_{2}$ adsorption/desorption profiles of CNT, N-CNT and five M-N-CNT catalysts. 


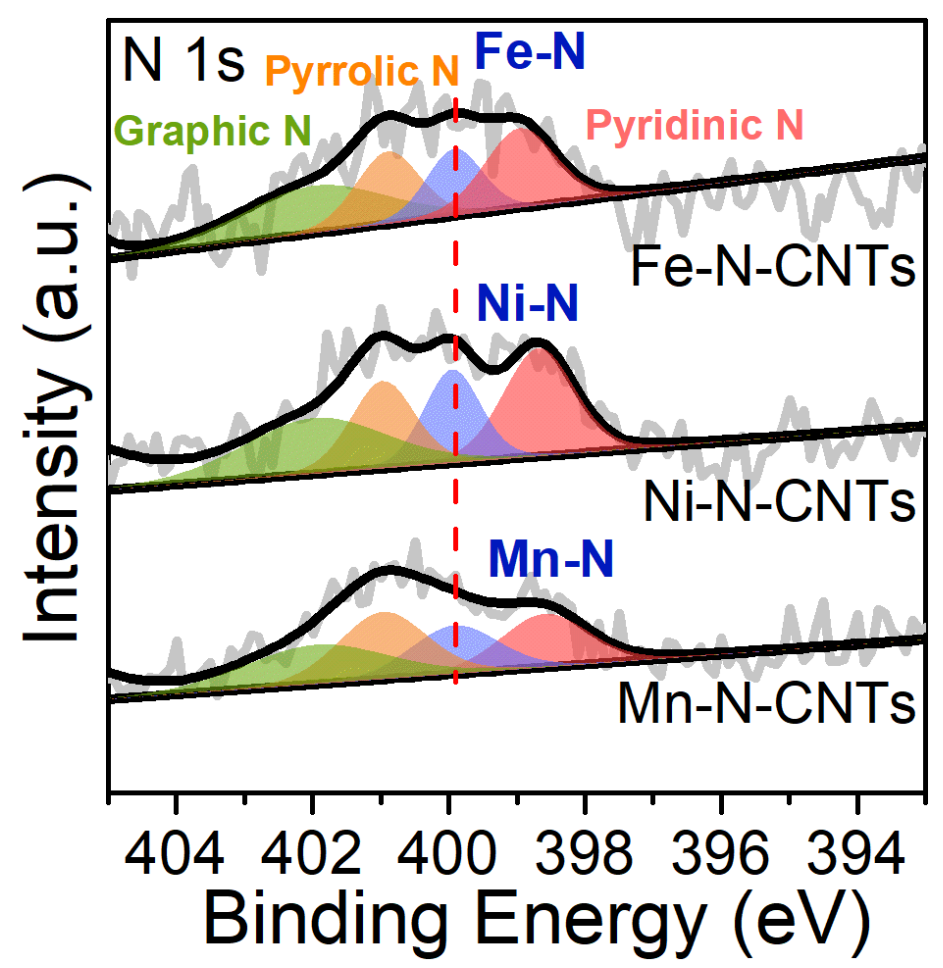

Figure S7. XPS spectra of N 1s for M-N-CNT catalysts. 

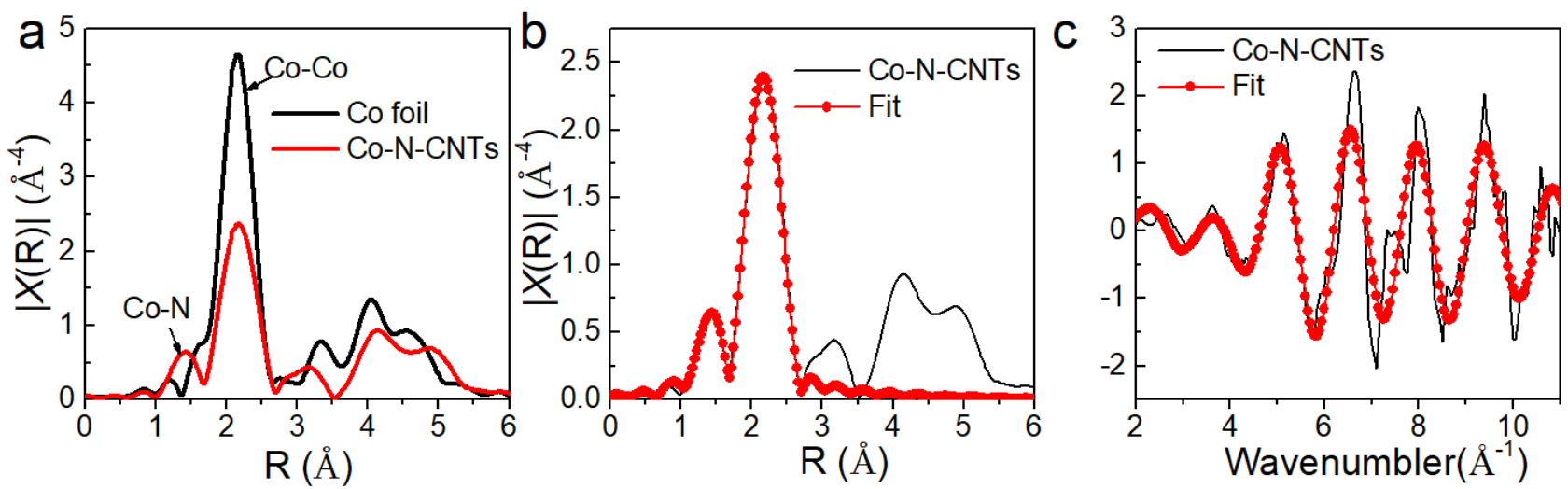

Figure S8. (a) Fourier transform (FT) $\mathrm{k}^{3}$-weighted $\chi(\mathrm{k})$-function of the EXAFS spectra of the Co Kedge of the Co-N-CNTs; (b) Corresponding Co K-edge EXAFS fitting curve of Co-N-CNTs; (c) quantitative EXAFS fitting curve at K space. 

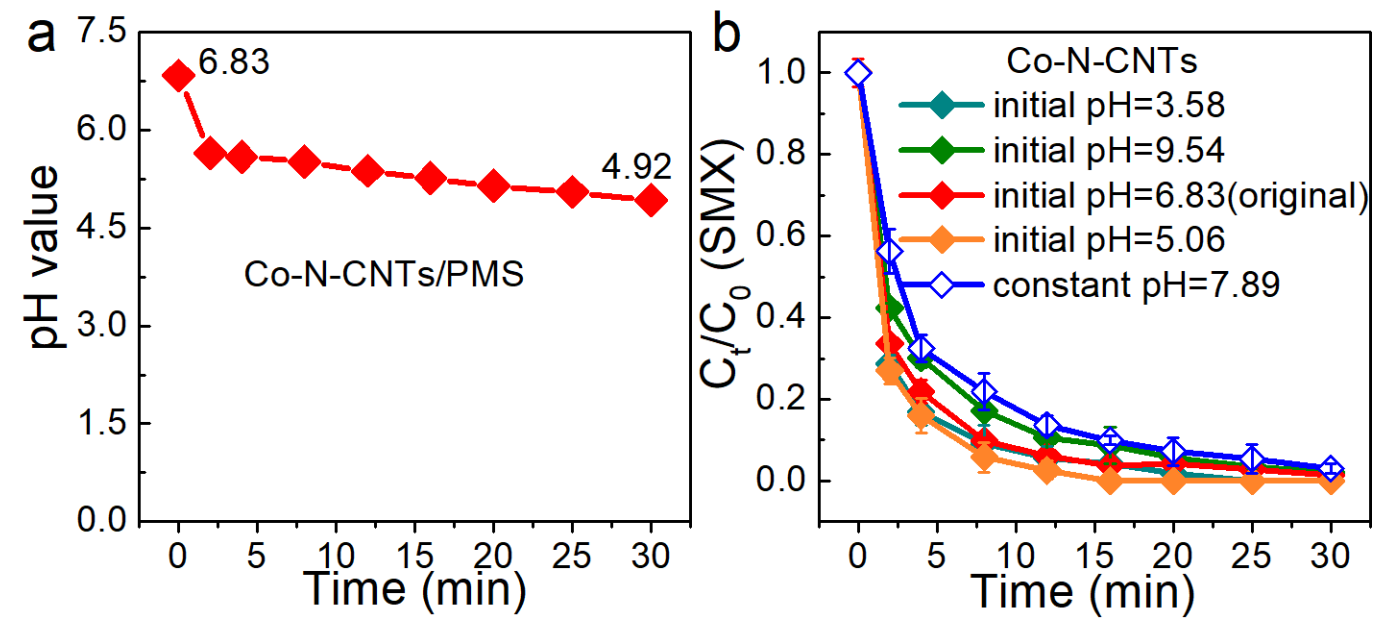

Figure S9. (a) $\mathrm{pH}$ changes during SMX oxidation; (b) negligible effect of $\mathrm{pH}$ on SMX oxidation in the Co-N-CNTs/PMS system; Reaction conditions: $[\mathrm{SMX}]_{0}=10 \mathrm{mg} \mathrm{L}^{-1}$, [catalyst] $=0.1 \mathrm{~g} \mathrm{~L}^{-1}$, $[\mathrm{PMS}]_{0}=1 \mathrm{mM}$, [Borate $]_{\text {buffer }}=0.2 \mathrm{M}$. 

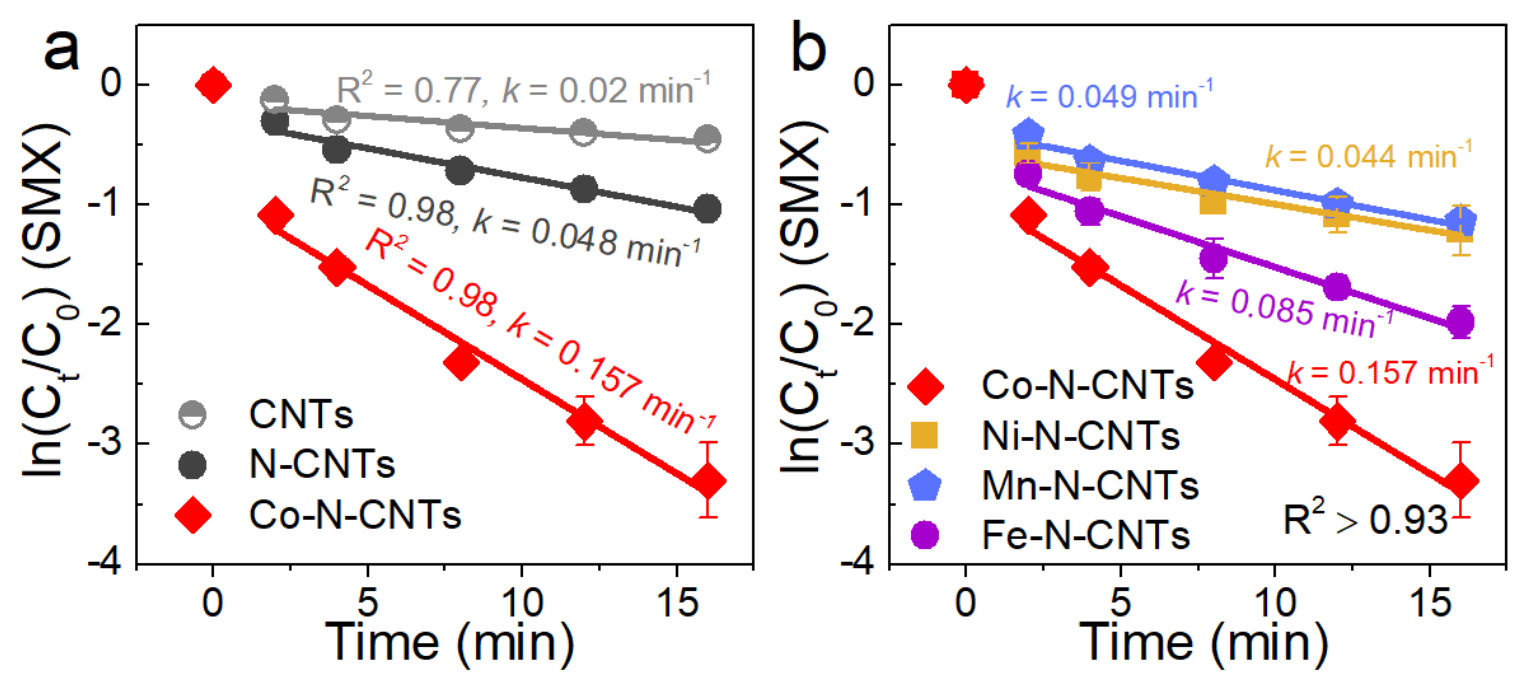

Figure S10. The first-order kinetics of SMX oxidation in CNTs/PMS, N-CNTs/PMS and different MN-CNTs/PMS systems. 


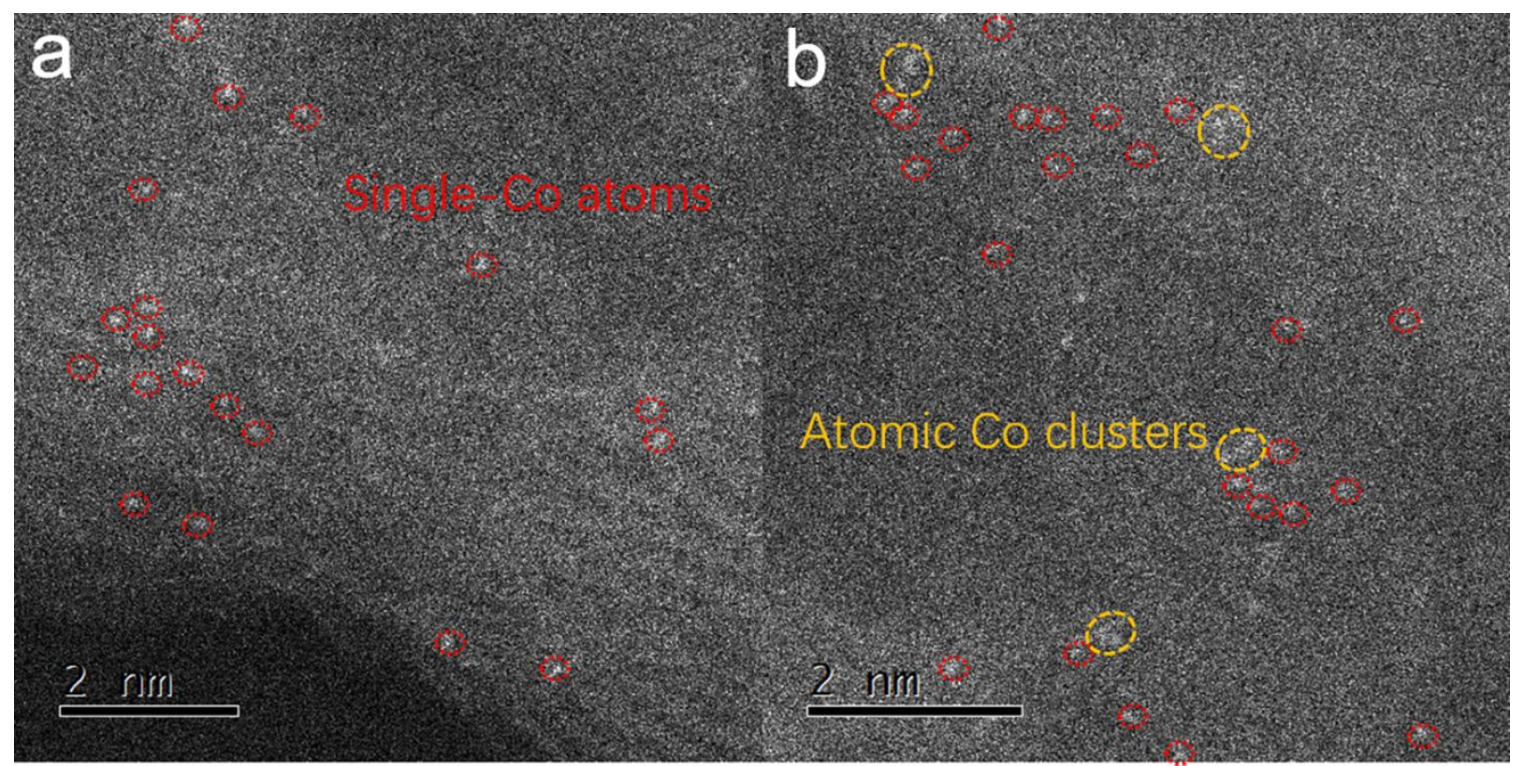

Figure S11. HAAD-STEM images for Co-N-CNTs after hot acid etching $\left(5 \mathrm{M} \mathrm{H}_{2} \mathrm{SO}_{4}, 7 \mathrm{~h}, 80{ }^{\circ} \mathrm{C}\right)$. 

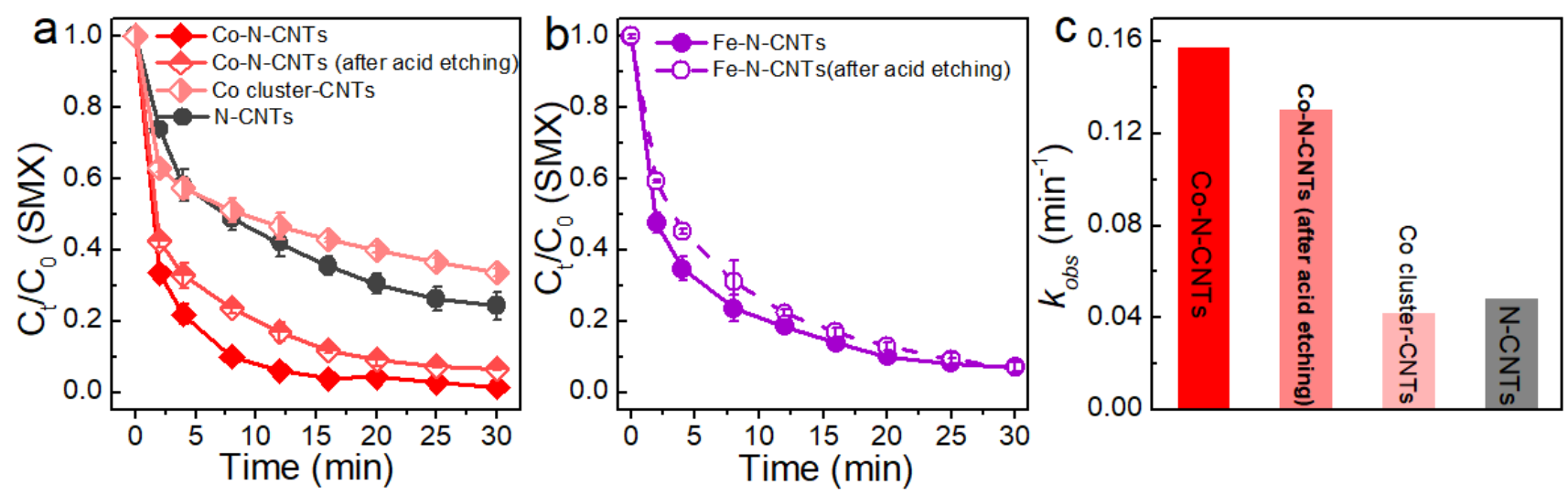

Figure S12. Comparison of (a) catalytic activities of Co-N-CNTs, Co-N-CNTs after hot acid etching, Co cluster-CNTs and (b) Fe-N-CNTs after hot acid etching (c) The reaction rate constants $\left(k_{o b s}\right)$ of Co$\mathrm{N}-\mathrm{CNTs}$, Co-N-CNTs after hot acid etching, Co cluster-CNTs and N-CNTs. 

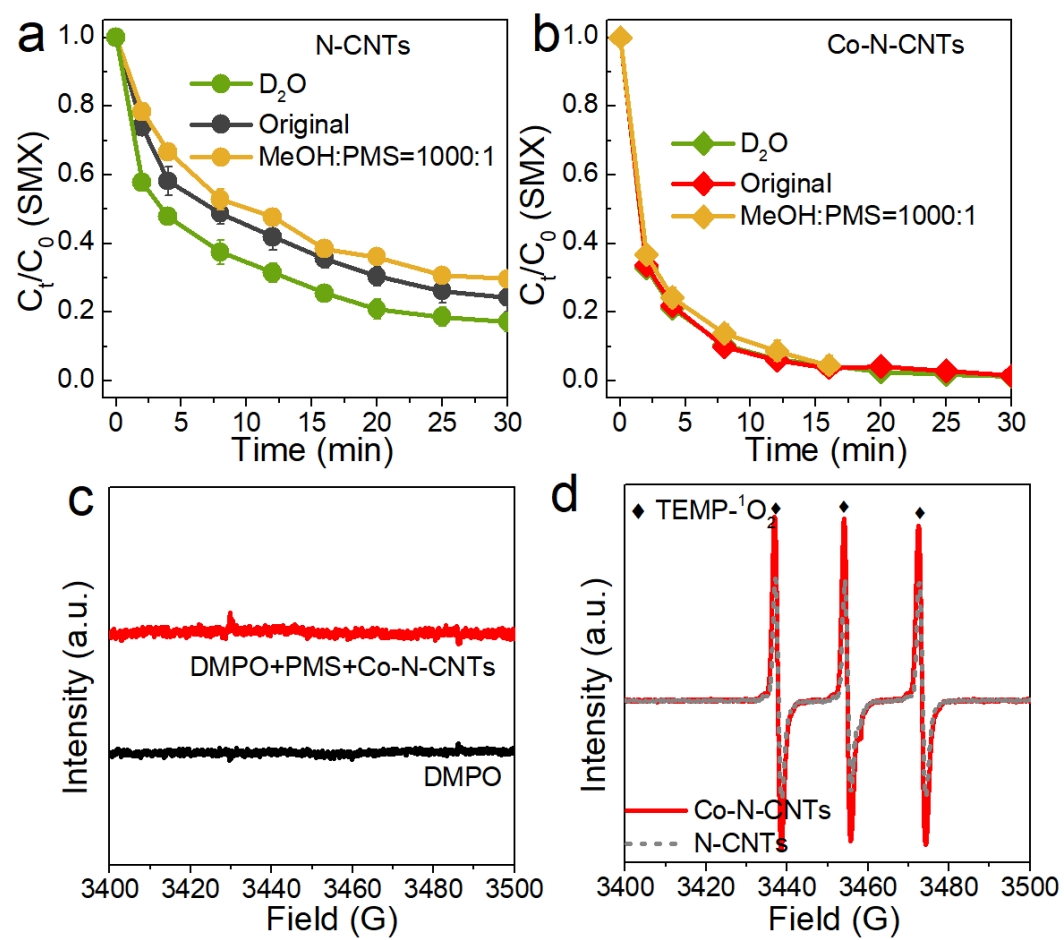

Figure S13. Quenching experiments in (a) N-CNTs/PMS system and (b) Co-N-CNTs/PMS system; EPR spectra for (c) hydroxyl radicals and (d) singlet oxygen in different reaction systems ( $\mathrm{t}=10 \mathrm{~min})$. 

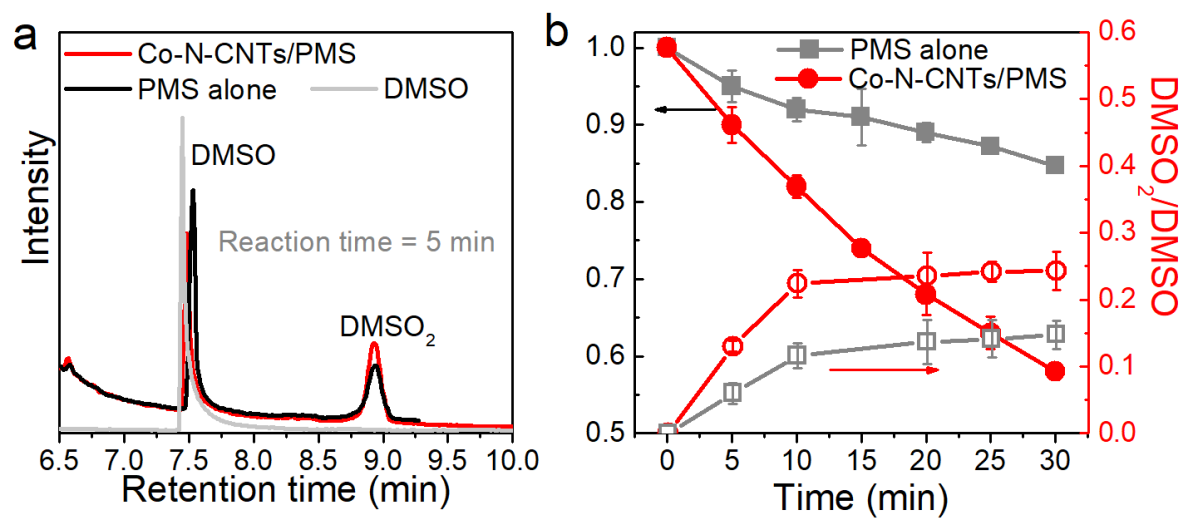

Figure S14. (a) GC-MS analysis for $\mathrm{DMSO}$ and $\mathrm{DMSO}_{2}$ at reaction time $=5 \mathrm{~min}$ in different systems; (b) DMSO degradation and $\mathrm{DMSO}_{2}$ conversion obtained at different reaction time in different systems; Reaction conditions: $[\mathrm{DMSO}]_{0}=20 \mu \mathrm{M}$, [catalyst $]=0.1 \mathrm{~g} \mathrm{~L}^{-1},[\mathrm{PMS}]_{0}=1 \mathrm{mM}, \mathrm{T}=25^{\circ} \mathrm{C}$. 

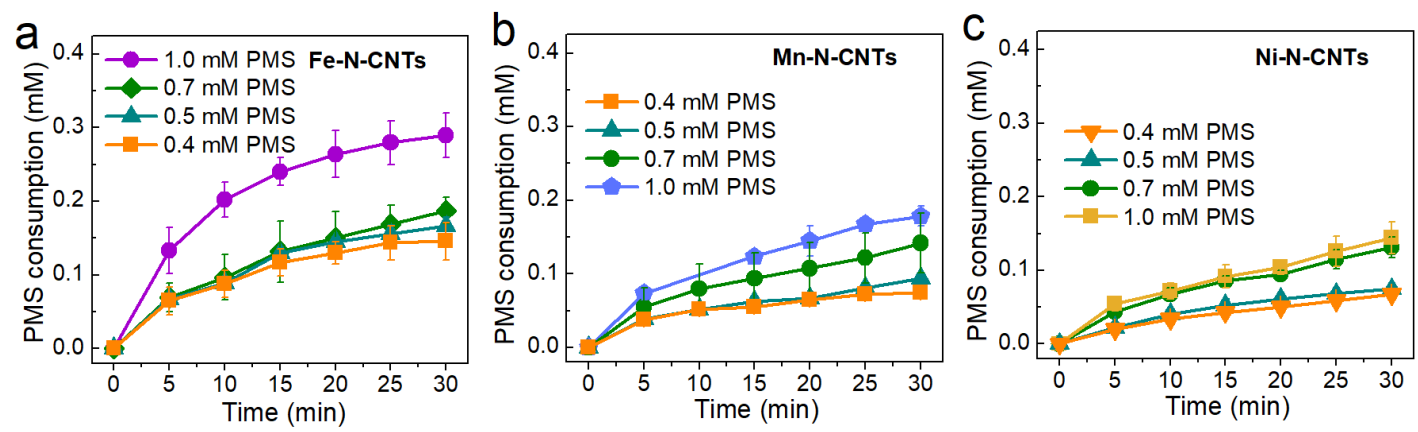

Figure S15. PMS adsorption in M-N-CNTs/PMS systems (M=Fe, Mn, Ni). 


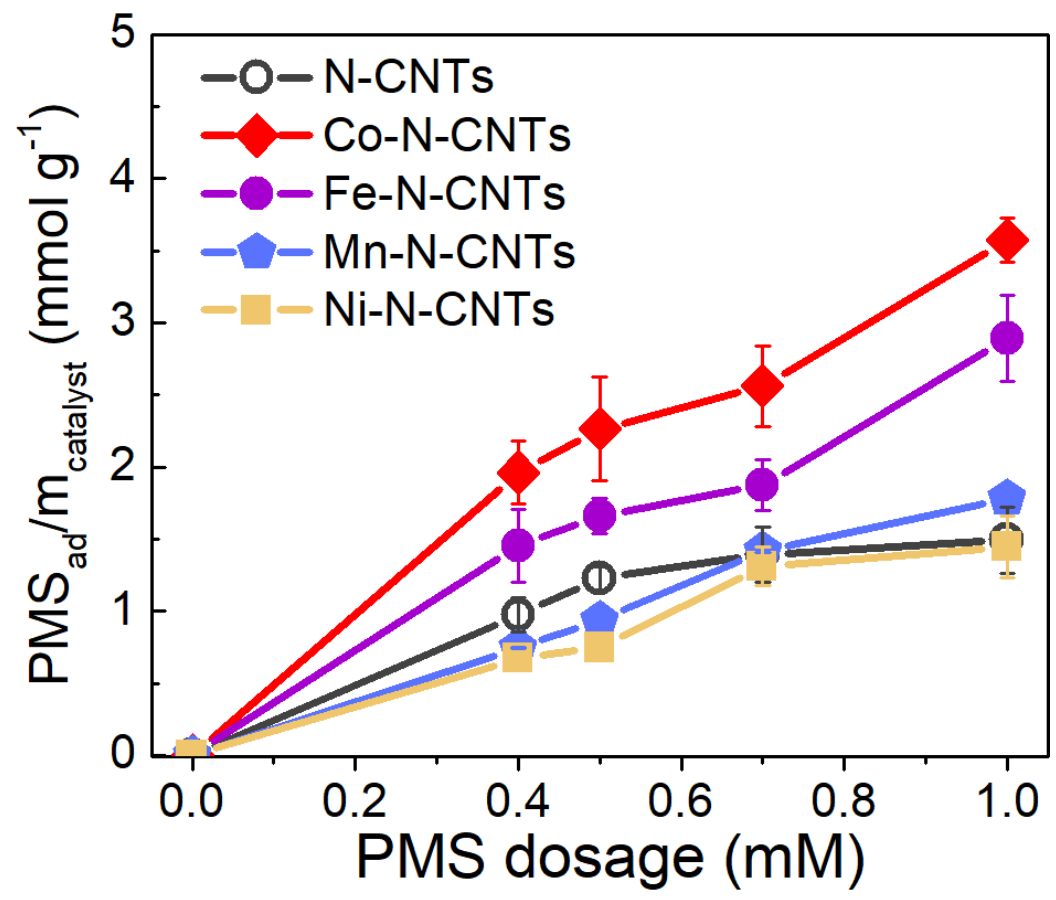

Figure S16. PMS adsorption over M-N-CNT catalysts. 

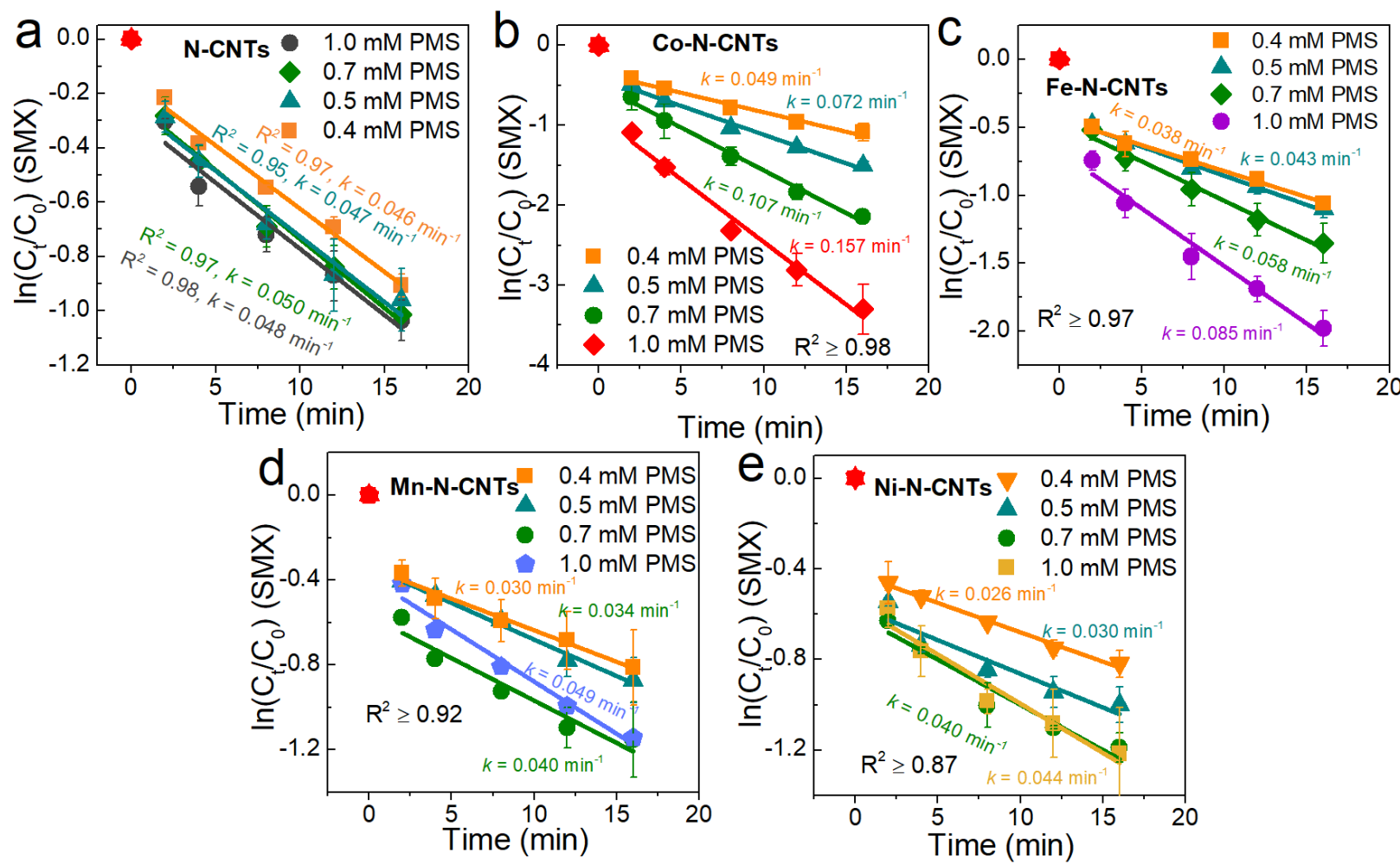

Figure S17. The first-order kinetics of SMX oxidation in N-CNTs/PMS and M-N-CNTs $(\mathrm{M}=\mathrm{Co}, \mathrm{Fe}$, $\mathrm{Mn}, \mathrm{Ni}) / \mathrm{PMS}$ systems with different PMS dosages. [SMX $]_{0}=10 \mathrm{mg} \mathrm{L}^{-1}$, [catalyst] $=0.1 \mathrm{~g} \mathrm{~L}^{-1}$, $[\mathrm{MeOH}]_{0}=1 \mathrm{M}, \mathrm{pH}_{\text {initial }}=6.8, \mathrm{~T}=25^{\circ} \mathrm{C}$. 


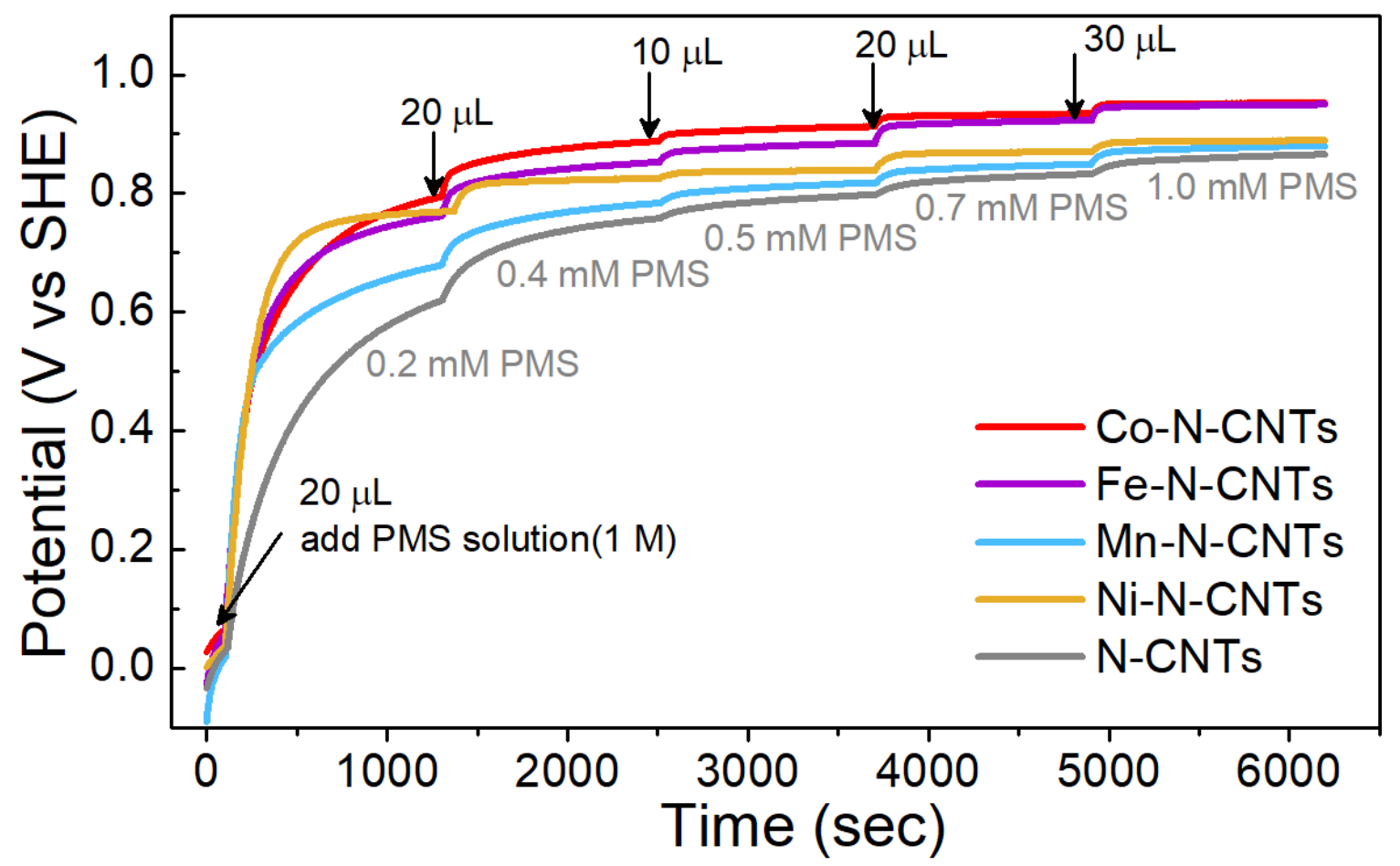

Figure S18. Open-circuit potential curves with different PMS dosages on CNT and M-N-CNT electrodes. 


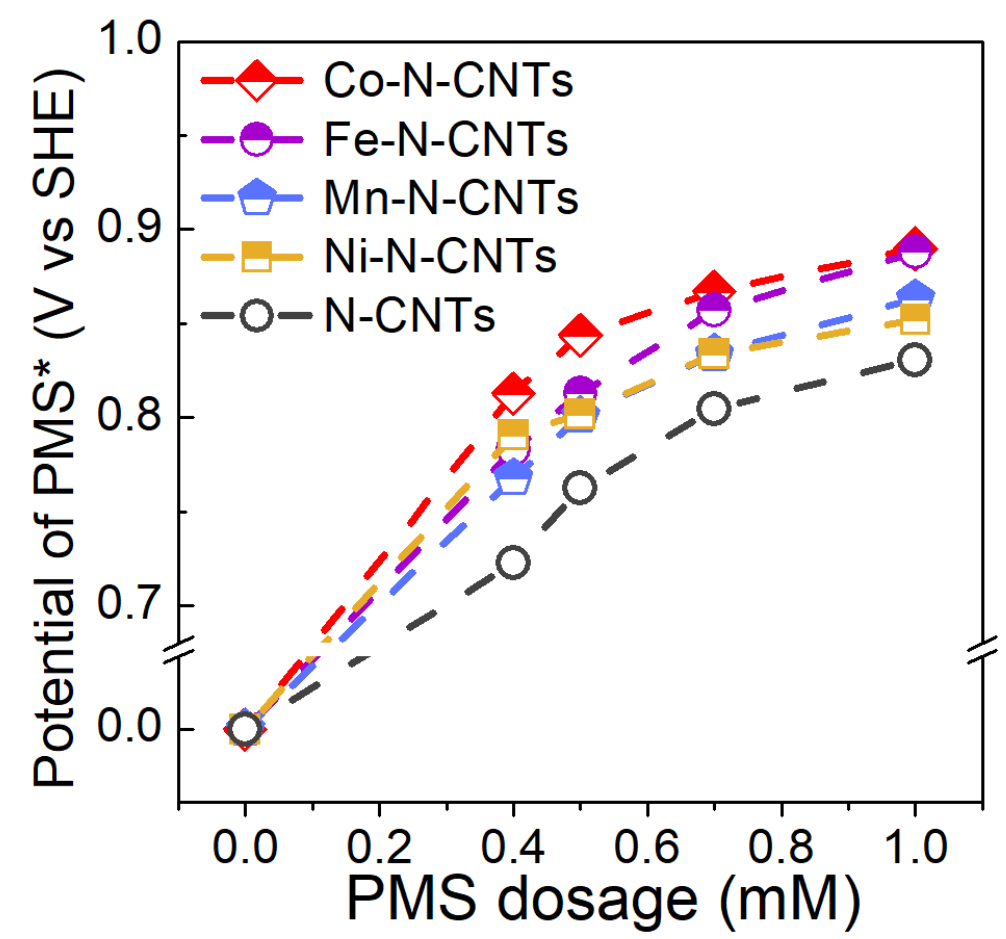

Figure S19. M-PMS* potentials in N-CNT/PMS and M-N-CNTs/PMS systems with different PMS dosages. 


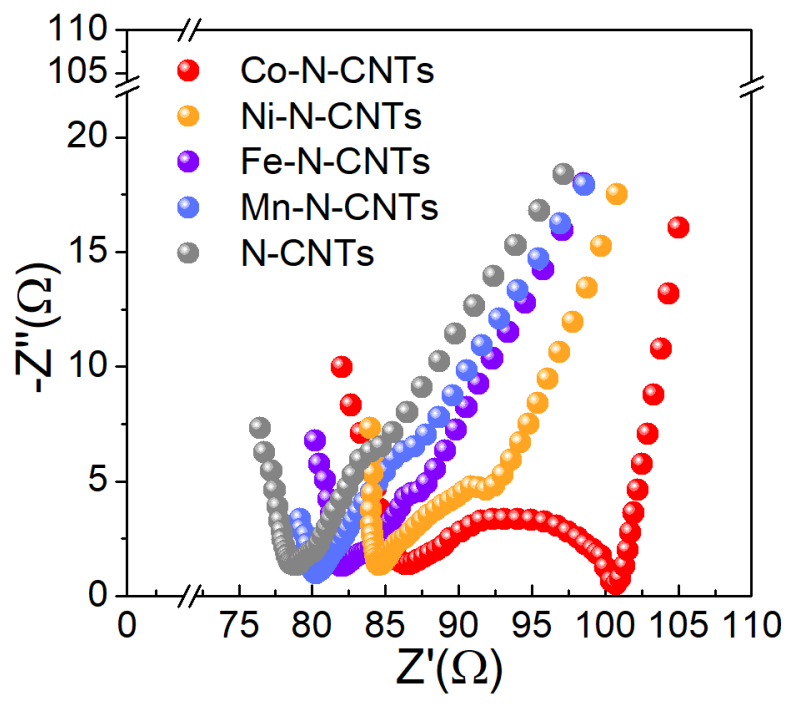

Figure S20. The electrochemical impedance spectroscopy (EIS) plots of M-N-CNTs and N-CNTs electrodes recorded at $-0.3 \mathrm{~V}$ vs $\mathrm{Ag} / \mathrm{AgCl}$ in $50 \mathrm{mM} \mathrm{Na}_{2} \mathrm{SO}_{4}$ solution. 

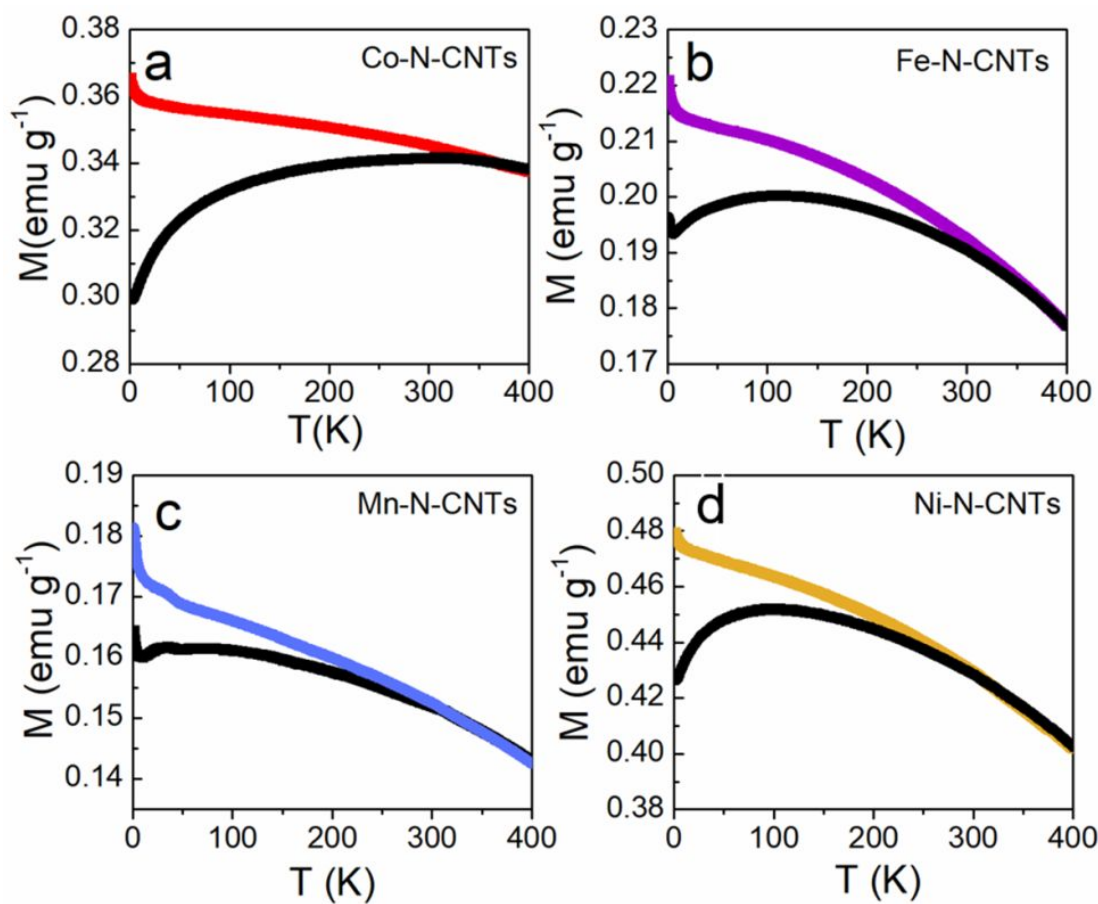

Figure S21. ZFC/FC curves over different M-N-CNT catalysts measured at $1 \mathrm{kOe}$. 


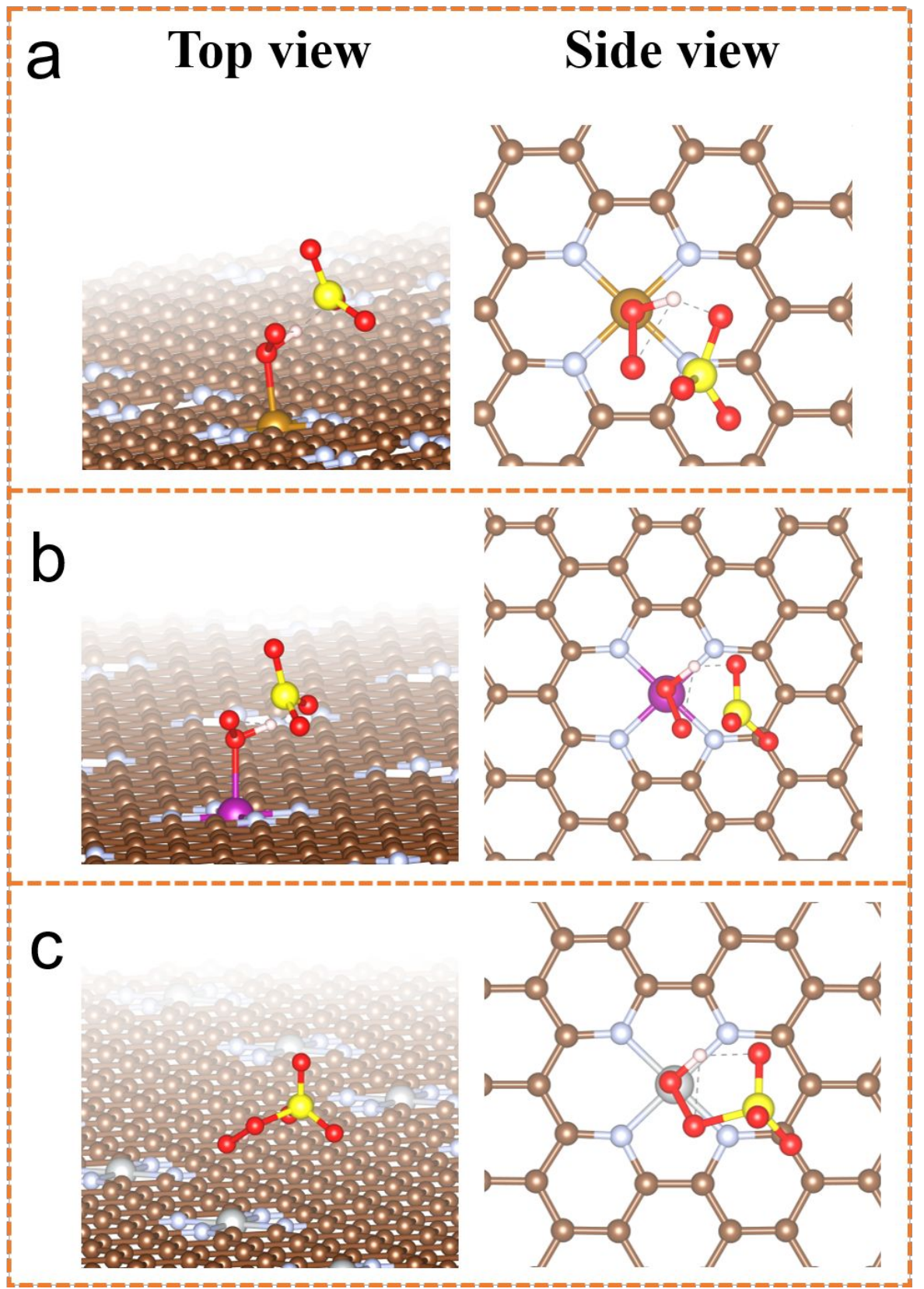

Figure S22. The configuration of PMS adsorption on (a) Fe-N-CNTs; (b) Mn-N-CNTs and (c) Ni-NCNTs. 
Table S1. The specific surface areas (SSAs) for CNT, N-CNT and M-N-CNT catalysts and metal contents in M-N-CNTs and Co cluster-CNTs detected by ICP-MS measurement.

\begin{tabular}{ccc}
\hline Samples & $\mathbf{S S A} / \mathbf{m}^{\mathbf{2}} \mathbf{g}^{\mathbf{1}}$ & Metal contents/wt\% \\
\hline CNTs & 183.2 & 0 \\
N-CNTs & 185.4 & 0 \\
Co-N-CNTs & 178.5 & 0.06 \\
Fe-N-CNTs & 170.6 & 0.07 \\
Mn-N-CNTs & 170.4 & 0.05 \\
Ni-N-CNTs & 162.8 & 0.30 \\
Co-N-CNTs (after hot acid etching) & -- & 0.01 \\
Fe-N-CNTs (after hot acid etching) & -- & 0.03 \\
Co cluster-CNTs & -- & 0.10 \\
Co cluster-CNTs (after hot acid etching) & -- & 0.05 \\
\hline
\end{tabular}


Table S2. The contents of different elements on the surface of different catalysts summarized from the XPS results.

\begin{tabular}{cccccccc}
\hline Samples & C(at\%) & O(at\%) & N (at\%) & $\begin{array}{c}\text { Graphitic } \\
\text { N (at\%) }\end{array}$ & $\begin{array}{c}\text { Pyridinic } \\
\text { N (at\%) }\end{array}$ & $\begin{array}{c}\text { Pyrrolic } \\
\text { N (at\%) }\end{array}$ & M-N(at\%) \\
\hline CNTs & -- & -- & 0 & 0 & 0 & 0 & 0 \\
N-CNTs & 98.87 & 0.85 & 0.28 & 0.085 & 0.094 & 0.101 & 0 \\
Co-N-CNTs & 98.35 & 1.22 & 0.43 & 0.141 & 0.134 & 0.088 & 0.067 \\
Fe-N-CNTs & 98.28 & 1.35 & 0.38 & 0.124 & 0.103 & 0.084 & 0.069 \\
Mn-N-CNTs & 98.27 & 1.31 & 0.52 & 0.143 & 0.119 & 0.150 & 0.108 \\
Ni-N-CNTs & 98.18 & 1.23 & 0.50 & 0.151 & 0.145 & 0.105 & 0.099 \\
\hline
\end{tabular}


Table S3. Structural parameters with errors of the samples obtained by fitting the EXAFS data: average coordination number $(\mathrm{N})$, path distance $(\mathrm{R})$, Debye-Waller factor $\left(\sigma^{2}\right)$, threshold energy correction $(\Delta \mathrm{E})$, and the R-Factor of the fitting.

\begin{tabular}{ccccccc}
\hline & Path & $\mathbf{N}$ & $\mathbf{\Delta E}(\mathbf{e V})$ & $\mathbf{1 0 0 \times R}(\AA)$ & $\mathbf{1 0}^{\mathbf{3}} \times \boldsymbol{\sigma}^{\mathbf{2}}\left(\AA^{2}\right)$ & R-factor \\
& & & & & & \\
\hline Co foil & Co-Co & 12 & $7.53(0.49)$ & $248.9(0.3)$ & $6.04(0.41)$ & 0.004 \\
Co-N-CNTs & Co-N & $0.67(0.49)$ & $9.79(2.22)$ & $178.4(4.1)$ & $4.40(2.59)$ & 0.005 \\
& Co-Co & $5.74(0.75)$ & $9.79(2.22)$ & $249.9(0.8)$ & $4.67(2.09)$ & \\
\hline
\end{tabular}


Table S4. The spin states, theoretical $\mu_{\text {eff }}$ and experimental $\mu_{\text {eff }}$ for M-N-CNTs catalysts.

\begin{tabular}{cccc}
\hline Samples & Spin state & Theoretical $\boldsymbol{\mu}_{\text {eff }}\left(\boldsymbol{\mu}_{\mathrm{B}}\right)$ & Experimental $\boldsymbol{\mu}_{\text {eff }}\left(\boldsymbol{\mu}_{\mathrm{B}}\right)$ \\
\hline Co(II)-N-CNTs & $\mathrm{S}=3 / 2$ & 3.87 & \\
Co(II)-N-CNTs & $\mathrm{S}=1 / 2$ & 1.73 & \multirow{2}{*}{4.34} \\
Co(III)-N-CNTs & $\mathbf{S}=\mathbf{2}$ & $\mathbf{4 . 9 0}$ & \\
Co(III)-N-CNTs & $\mathrm{S}=0$ & 0 & \multirow{2}{*}{1.75} \\
\hline Fe(II)-N-CNTs & $\mathrm{S}=2$ & 4.90 & \\
Fe(II)-N-CNTs & $\mathrm{S}=0$ & 0 & \multirow{2}{*}{1.69} \\
Fe(III)-N-CNTs & $\mathbf{S}=\mathbf{1} / \mathbf{2}$ & $\mathbf{1 . 7 3}$ & \multirow{2}{*}{2.24} \\
\hline Mn(II)-N-CNTs & $\mathbf{S}=\mathbf{1} / \mathbf{2}$ & $\mathbf{1 . 7 3}$ & \\
Mn(II)-N-CNTs & $\mathrm{S}=5 / 2$ & 5.92 & \\
\hline Ni(II)-N-CNTs & $\mathbf{S}=\mathbf{1}$ & $\mathbf{2 . 8 3}$ & \\
Ni(II)-N-CNTs & $\mathrm{S}=0$ & 0 &
\end{tabular}




\section{References:}

(1) Hu, P.; Su, H.; Chen, Z.; Yu, C.; Li, Q.; Zhou, B.; Alvarez, P. J. J.; Long, M., Selective degradation of organic pollutants using an efficient metal-free catalyst derived from carbonized polypyrrole via peroxymonosulfate activation. Environ. Sci. Technol. 2017, 51 (19), 11288-11296.

(2) Du, N.; Liu, Y.; Li, Q.; Miao, W.; Wang, D.; Mao, S., Peroxydisulfate activation by atomicallydispersed Fe-Nx on N-doped carbon: Mechanism of singlet oxygen evolution for nonradical degradation of aqueous contaminants. Chem. Eng. J. 2020, 127545.

(3) Ren, W.; Nie, G.; Zhou, P.; Zhang, H.; Duan, X.; Wang, S., The intrinsic nature of persulfate activation and N-doping in carbocatalysis. Environ. Sci. Technol. 2020, 54 (10), 6438-6447.

(4) Kresse, G.; Hafner, J., Ab initio molecular-dynamics simulation of the liquid-metal--amorphoussemiconductor transition in germanium. Phys. Rev. B 1994, 49 (20), 14251-14269.

(5) Kresse, G.; Furthmüller, J., Efficiency of ab-initio total energy calculations for metals and semiconductors using a plane-wave basis set. Comput. Mater. Sci. 1996, 6 (1), 15-50.

(6) Kresse, G.; Furthmüller, J., Efficient iterative schemes for ab initio total-energy calculations using a plane-wave basis set. Phys. Rev. B 1996, 54 (16), 11169-11186.

(7) Blöchl, P. E.; Margl, P.; Schwarz, K., Ab Initio molecular dynamics with the projector augmented wave method. In Chemical Applications of Density-Functional Theory, American Chemical Society: 1996; Vol. 629, pp 54-69.

(8) Perdew, J. P.; Burke, K.; Ernzerhof, M., Generalized gradient approximation made simple. Phys. Rev. Lett. 1996, 77 (18), 3865-3868.

(9) Bader, R. F. W.; Nguyen-Dang, T. T., Quantum theory of atoms in molecules-dalton revisited. In Advances in Quantum Chemistry, Löwdin, P.-O., Ed. Academic Press: 1981; Vol. 14, pp 63-124.

(10) Tang, W.; Sanville, E.; Henkelman, G., A grid-based Bader analysis algorithm without lattice bias. J. Phys. Condensed Matter 2009, 21 (8), 084204. 